\title{
Sports Injuries in the Services 1969-1980
}

\author{
Miss J A Tointon,
}

Ministry of Defence (Stats (G) 4), Stanmore

SUMMARY: This paper reviews sports injuries in the Armed Services 1969-1980 to establish their incidence and to analyse trends over time. There were on average 2135 sports injuries per year showing a falling trend over time until 1979 and then rising. Playing soccer was the cause of $43 \%$ of the sports injuries over the years 1969-1980. By far the greatest proportion $85 \%$ the injuries occurred in the under 30 age group.

The number of medical discharges fell until 1974 when it rose to a new level of between 22 and 31 per year. The number of deaths showed no particular trend over time but half of the deaths were caused by drowning.

\section{Introduction}

Injuries due to sport comprise on average $3.5 \%$ of all cases of sickness and $17-18 \%$ of all injuries, which represents a sizeable amount of manpower wastage. A study by Oelman et al into boxing injuries in the Army ${ }^{1}$ prompted this more comprehensive paper covering all sports in all three Services.

The aim of this paper is fourfold:

1. To describe the annual incidence of sports injury requiring admission to a medical establishment and deaths due to injury from 1969 to 1980 inclusive.

2. To determine the contribution, in absolute terms, each sport made to hospital admission, including discharges and deaths.

3. To describe the age distribution of sports injuries.

4. To determine the site of injury in order of frequency.

\section{Methods}

The medical statistics branch of the Ministry of Defence (Stats(G)4) has a computerised database called TRIMEDS (Tri-Service and Medical Statistics). TRIMEDS contains records and deaths, medical discharges and sickness lasting two days or more for serving personnel. Each record contains the coded information from the MOD form $F$ Med 14.

From these computer-held records were retrieved details of all male serving personnel who had been admitted to a medical establishment (whether hospital, medical reception station or any other medical unit), or who had been medically discharged or had died as a result of a sporting accident between the years 1969-1980 inclusive. Only records of injuries were extracted - the cause of sportsrelated diseases is not coded.

The extracted records were the major source of information but where further detail was needed permission was obtained to examine the relevant records held at Stag (G)4, i.e. F Med 29s and their contents.

The manpower figures were obtained from Stats (M공

\section{Results}

Time Trends. Table I shows that during the 12 ye period studied there were 25,625 sports injuries recor $\$$ ed, giving an average of 2,135 cases per year or 6.5 ift juries per 1,000 average strength* per year.

Table I

Sports Injuries and rates per 1,000 strength

\begin{tabular}{|c|c|c|c|}
\hline Year & No. Cases & $\begin{array}{l}\text { Strength } \\
(1,000 s)\end{array}$ & $\begin{array}{r}\text { Rate/1,000 } \\
\text { Strength }\end{array}$ \\
\hline $\begin{array}{l}1969 \\
1970 \\
1971 \\
1972 \\
1973 \\
1974 \\
1975 \\
1976 \\
1977 \\
1978 \\
1979 \\
1980 \\
\end{array}$ & $\begin{array}{l}2959 \\
2631 \\
2484 \\
2355 \\
2156 \\
1992 \\
1996 \\
1835 \\
1812 \\
1661 \\
1725 \\
2019\end{array}$ & $\begin{array}{l}362.0 \\
354.2 \\
349.4 \\
352.1 \\
342.2 \\
327.2 \\
320.0 \\
318.5 \\
312.6 \\
304.5 \\
300.6 \\
308.7 \\
\end{array}$ & 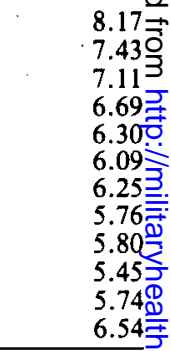 \\
\hline Totals & 25625 & 3952.0 & 6.48 윽 \\
\hline
\end{tabular}

Figure 1 illustrates the gradual fall in the incidence of sports injuries up to 1978 and then the increase in 1980 . More up-to-date material has not been studied to con-윽 firm the continuation of the upward trend.

Figure 2 demonstrates that from an initial downward으․ trend of discharges per 1,000 average strength there has $\tilde{N}$ been an approximate eight fold increase in discharges due to sports injuries.

If we examine the discharges due to sports injuries as a proportion of all injuries, Table II indicates that since् 1973 there is an apparent steady increase in the propor- 


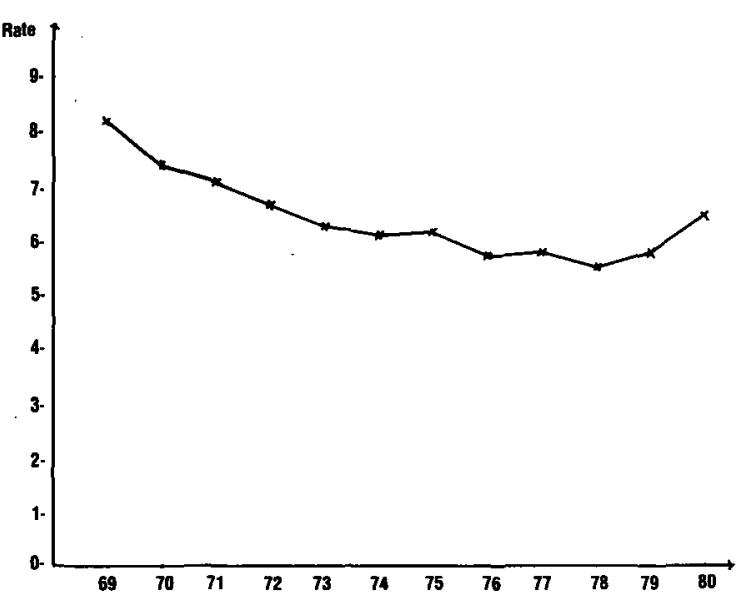

\begin{tabular}{|c|c|c|c|c|c|c|c|c|c|c|c|c|} 
Year & 69 & 70 & 71 & 72 & 73 & 74 & 75 & 76 & 77 & 78 & 79 & 80 \\
\hline Rate & $8 \cdot 17$ & $7 \cdot 43$ & $7 \cdot 11$ & $6 \cdot 69$ & $6 \cdot 30$ & $6 \cdot 09$ & $6 \cdot 25$ & $5 \cdot 76$ & $5 \cdot 80$ & $5 \cdot 45$ & $5 \cdot 74$ & $6 \cdot 54$
\end{tabular}

Fig. 1 Rates per 1,000 strength by year - Inpatients.

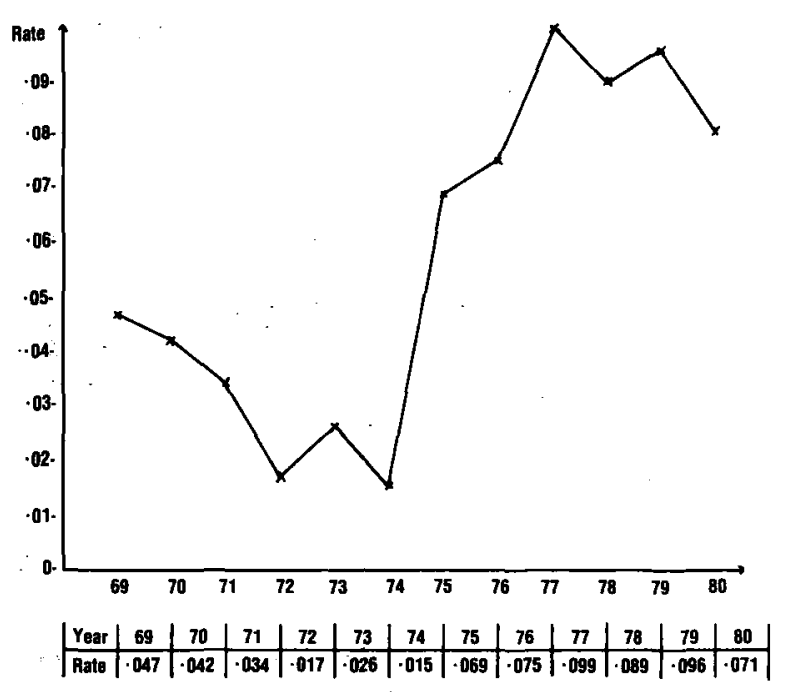

Fig. 2 Rates per 1,000 strength by year - Medical discharges.

There is no distinct trend in the annual death rate over the period examined as shown in Table III. This is to be expected in view of the small numbers involved.

Sports: Sports injuries were identified using the NATO cause of injury codes ${ }^{2}$.
Table II

Numbers discharged each year due to All injuries and Sports Injuries

\begin{tabular}{|c|c|c|c|}
\hline Year & $\begin{array}{c}\text { All } \\
\text { injuries }\end{array}$ & $\begin{array}{c}\text { Sports } \\
\text { injuries }\end{array}$ & $\begin{array}{l}\text { \% Sports Injuries } \\
\% \text { All Injuries }\end{array}$ \\
\hline $\begin{array}{l}1969 \\
1970 \\
1971 \\
1972 \\
1973 \\
1974 \\
1975 \\
1976 \\
1977 \\
1978 \\
1979 \\
1980\end{array}$ & $\begin{array}{l}\cdots \\
\cdots \\
272 \\
283 \\
285 \\
262 \\
280 \\
269 \\
199 \\
164\end{array}$ & $\begin{array}{r}17 \\
15 \\
12 \\
6 \\
9 \\
5 \\
22 \\
24 \\
31 \\
27 \\
29 \\
22\end{array}$ & 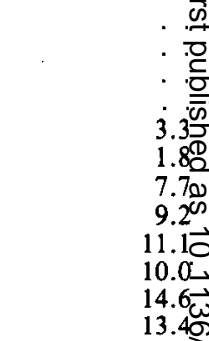 \\
\hline
\end{tabular}

. . Denotes not available

Table III

Death Rate due to Sports and Sport related Injuries $\frac{i}{\omega}$

\begin{tabular}{|c|c|c|}
\hline Year & No. Deaths & $\begin{array}{r}\text { Rate } / 1,000 \\
\text { Strength }\end{array}$ \\
\hline $\begin{array}{l}1969 \\
1970 \\
1971 \\
1972 \\
1973 \\
1974 \\
1975 \\
1976 \\
1977 \\
1978 \\
1979 \\
1980 \\
\end{array}$ & $\begin{array}{l}5 \\
4 \\
4 \\
9 \\
4 \\
1 \\
6 \\
0 \\
3 \\
3 \\
3 \\
6 \\
\end{array}$ & 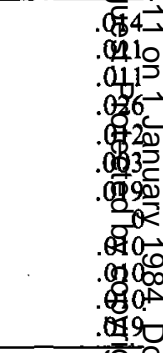 \\
\hline Total & 48 & .202 \\
\hline
\end{tabular}

Figure 3 illustrates the contribution each sport made in absolute terms to hospital admissions. Soccer, as is to $\mathbb{D}$ be expected, contributed the greatest percentage of admissions.

Figure 4 confirms the pre-eminence of soccer as a cause of medical discharges. It is worthy of note, however, that PT is responsible for almost one in five of the sportsrelated medical discharges.

In all 48 deaths were recorded as being attributable to sports injuries. Table IV shows the breakdown of deaths by cause/sport.

Age: Figure 5 shows that both injuries and strength peak at the age group 20-24 but the percentage of injuries falls more rapidly than strength for older age groups. This 3 . point is further illustrated by Table $\mathrm{V}$ which shows the injury rate per 1,000 average strength decreasing with age. $₹$

Table VI shows the rate per 1,000 average strength ofo sports injury discharges by age. There were no discharges amongst the over $50 \mathrm{~s}$ and the trend is falling.

Seventy seven percent of the deaths occurred before the age of $30-$ the greatest number occurring in the age. group 20-24. However when we examine the death rates 0 per 1,000 strength (Table VII) we note that the death rates ${ }_{\mathrm{C}}$ in the 40-44 and 45-49 age groups are almost comparableo to that of the younger age group. 


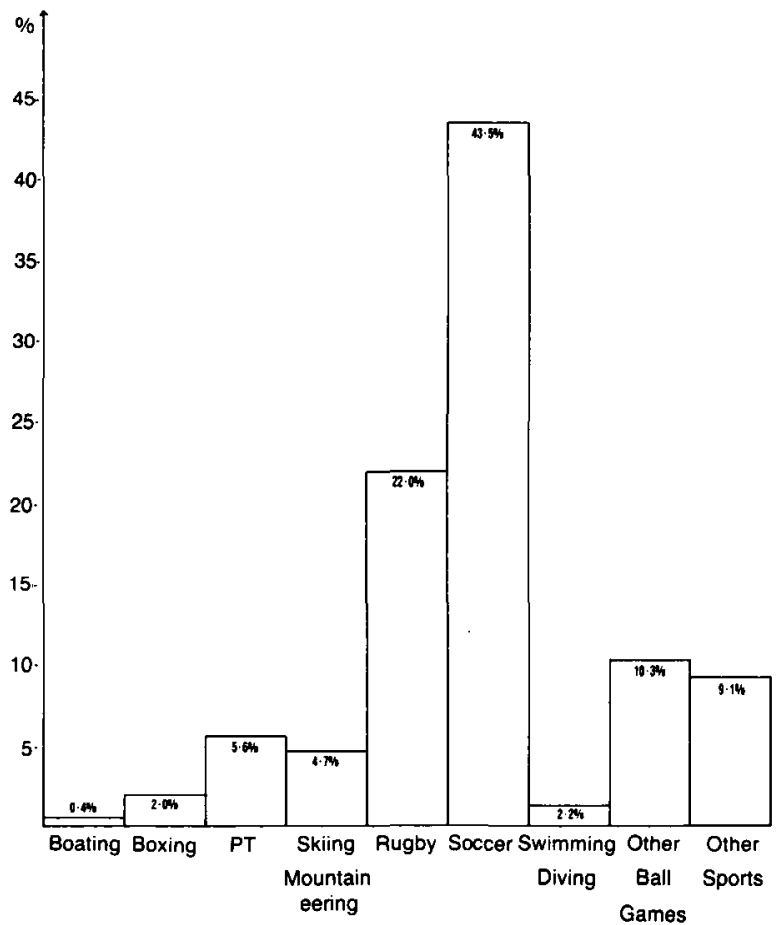

Fig. 3 Inpatients - Percentage by Sport.

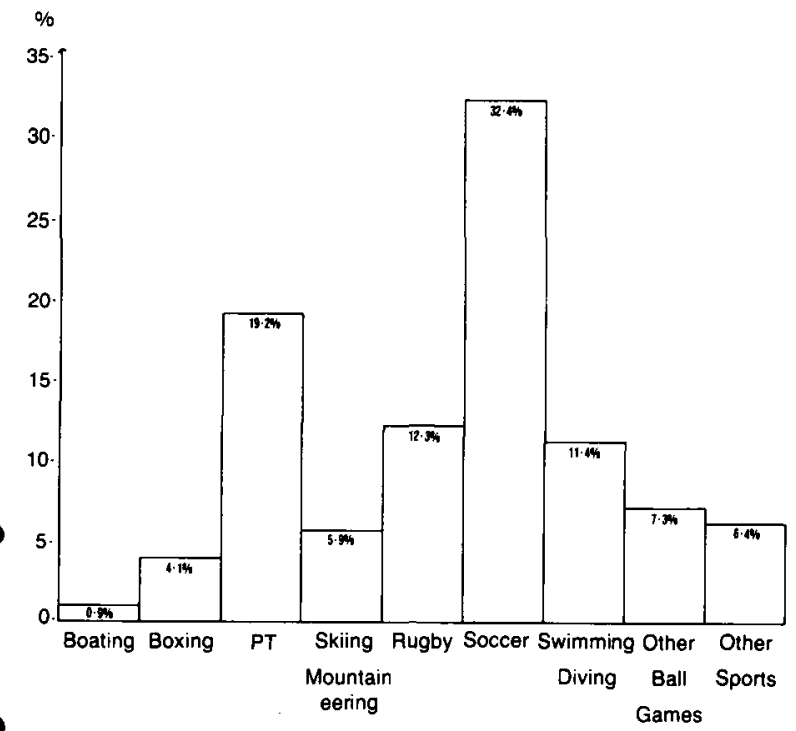

Fig. 4 Medical discharges - Percentage by Sport.

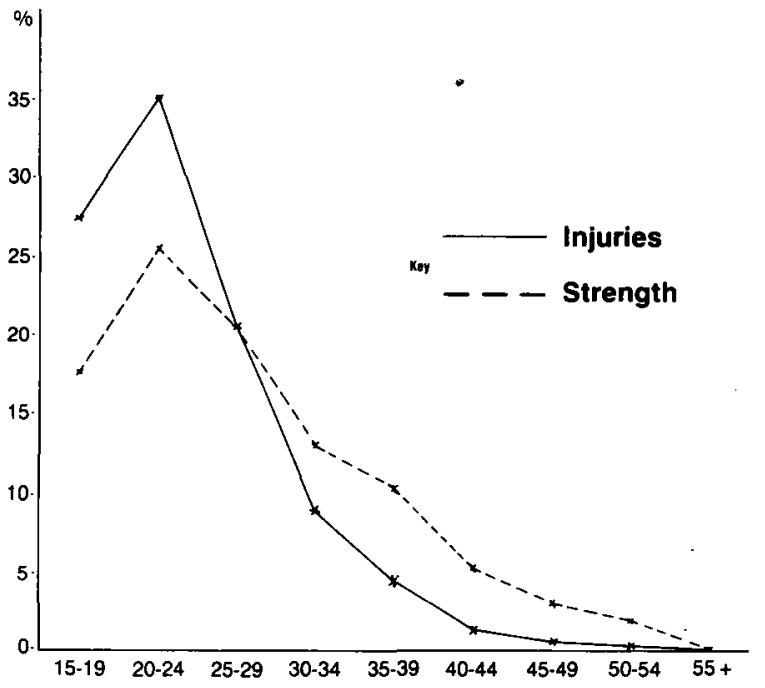

Fig. 5 Inpatients - Percentage Strength and Injuries by Age.

Table IV

Cause of Death

\begin{tabular}{|c|c|}
\hline Cause/Sport & No. of Deat \\
\hline $\begin{array}{l}\text { Swimming/Diving } \\
\text { Skiing/Mountaineering } \\
\text { Boating } \\
\text { Soccer } \\
\text { Other }\end{array}$ & 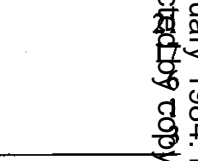 \\
\hline \multicolumn{2}{|l|}{ Total } \\
\hline Injury $R$ & \\
\hline
\end{tabular}

\begin{tabular}{|c|c|c|}
\hline Age Group & Injuries & $\begin{array}{l}\text { Rate } / 1,000 \\
\text { Strength }\end{array}$ \\
\hline $\begin{array}{c}15-19 \\
20-24 \\
25-29 \\
30-34 \\
35-39 \\
40-44 \\
45-49 \\
50-54 \\
55+ \\
\end{array}$ & $\begin{array}{r}7004 \\
9598 \\
5217 \\
2267 \\
1050 \\
332 \\
114 \\
39 \\
4 \\
\end{array}$ & $\begin{array}{r}9.963 \\
8.53 \\
6.46= \\
4.39 \\
2.563 \\
1.56 \\
0.930 \\
0.56 \\
0.00 \\
\end{array}$ \\
\hline \multicolumn{3}{|c|}{$\begin{array}{c}\text { Table VI } \\
\text { Discharged Rate analysed by Age }\end{array}$} \\
\hline Age Group & Discharges & $\begin{array}{r}\text { Rate } / 1,000 \\
\text { Strengtho }\end{array}$ \\
\hline $\begin{array}{r}15-19 \\
20-24 \\
25-29 \\
30-34 \\
35-39 \\
40-44 \\
45-49 \\
50-54 \\
55+ \\
\end{array}$ & $\begin{array}{r}59 \\
78 \\
45 \\
24 \\
7 \\
4 \\
2 \\
0 \\
0 \\
\end{array}$ & 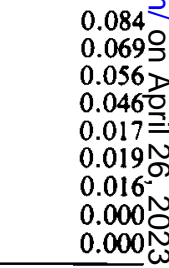 \\
\hline Total & 219 & 0.0550 \\
\hline
\end{tabular}


TABLE VII

Deaths analysed by Age

\begin{tabular}{ccc}
\hline Age & No $\cdot$ of Deaths & $\begin{array}{c}\text { Rate } / 1,000 \\
\text { Strength }\end{array}$ \\
\hline $15-19$ & 7 & $\cdot 010$ \\
$20-24$ & 22 & .020 \\
$25-29$ & 8 & .010 \\
$30-34$ & 3 & .006 \\
$35-39$ & 2 & .005 \\
$40-44$ & 4 & .019 \\
$45-49$ & 2 & .016 \\
$50-54$ & 0 & .000 \\
$55+$ & 0 & .000 \\
\hline Totals & 48 & .012 \\
\hline
\end{tabular}

Site: The sites of the injuries were determined from the ICD codes ${ }^{3}$, Table VIII gives the analysis of the frequency of injury.

The vast majority of admissions were caused by lower limb injuries with an average of some 1,200 cases per year. Head injuries are next most common, followed by upper limb and trunk injuries, with comparatively few internal and other injuries occurring. The pie chart in Figure 6 illustrates these proportions.

Of the 219 sports injury discharges nearly $40 \%$ were due to leg injuries, $22 \%$ due to 'other' injuries and $17.5 \%$ to spinal injuries. Head and upper limb injuries accounted

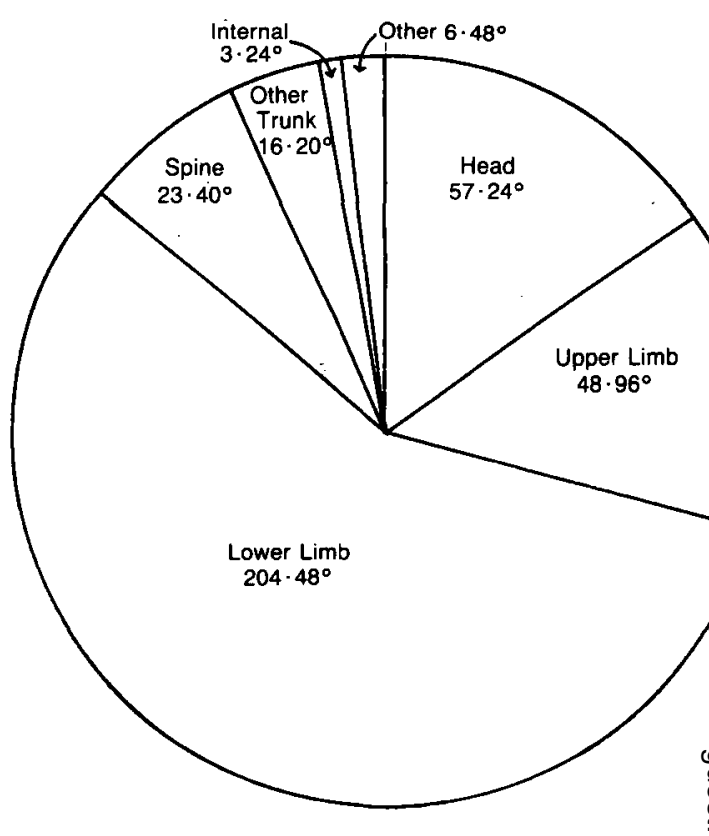

Fig. 6 Inpatients - By site of Injury.

TABLE VIII

Inpatient cases: Sites of Injury for each major sport/activity

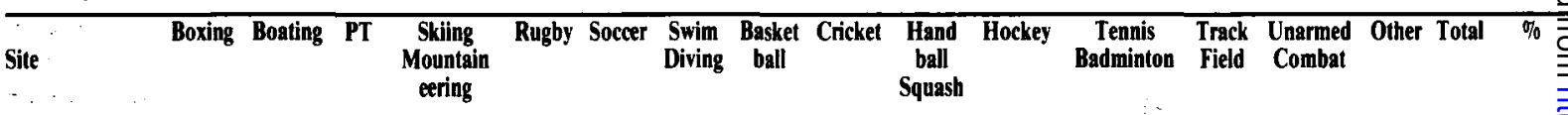

\begin{tabular}{|c|c|c|c|c|c|c|c|c|c|c|c|c|c|c|c|c|c|}
\hline $\begin{array}{l}\text { Head } \\
\text { Upper Limb } \\
\text { Lower Limb } \\
\text { Spine } \\
\text { Other Trunk } \\
\text { Internal } \\
\text { Other }\end{array}$ & $\begin{array}{r}16 \\
20 \\
34 \\
20 \\
8 \\
1 \\
11\end{array}$ & $\begin{array}{r}365 \\
74 \\
33 \\
10 \\
14 \\
10 \\
13\end{array}$ & $\begin{array}{r}167 \\
168 \\
696 \\
252 \\
114 \\
4 \\
42\end{array}$ & $\begin{array}{r}53 \\
61 \\
972 \\
33 \\
48 \\
9 \\
37\end{array}$ & $\begin{array}{r}1281 \\
983 \\
2576 \\
310 \\
346 \\
69 \\
78\end{array}$ & $\begin{array}{r}1170 \\
1533 \\
7516 \\
361 \\
363 \\
98 \\
118\end{array}$ & $\begin{array}{r}191 \\
41 \\
129 \\
127 \\
18 \\
5 \\
54\end{array}$ & $\begin{array}{r}33 \\
35 \\
327 \\
25 \\
18 \\
4 \\
4\end{array}$ & $\begin{array}{r}148 \\
57 \\
157 \\
38 \\
27 \\
2 \\
3\end{array}$ & $\begin{array}{r}211 \\
42 \\
402 \\
98 \\
24 \\
2 \\
15\end{array}$ & $\begin{array}{r}163 \\
123 \\
296 \\
44 \\
31 \\
1 \\
4\end{array}$ & $\begin{array}{r}44 \\
12 \\
179 \\
50 \\
5 \\
1 \\
4\end{array}$ & $\begin{array}{r}8 \\
21 \\
137 \\
31 \\
18 \\
1 \\
11\end{array}$ & $\begin{array}{r}42 \\
101 \\
176 \\
37 \\
31 \\
5 \\
5\end{array}$ & $\begin{array}{r}195 \\
220 \\
929 \\
209 \\
81 \\
15 \\
61\end{array}$ & $\begin{array}{r}4087 \\
3491 \\
14559 \\
1645 \\
1146 \\
227 \\
470\end{array}$ & 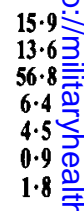 \\
\hline Total & 110 & 519 & 1443 & 1213 & 5643 & 11159 & 575 & 446 & 432 & 794 & 662 & 295 & 227 & 397 & 1710 & 25625 & $100 \cdot 03$ \\
\hline$\%$ & 0.4 & $2 \cdot 0$ & $5 \cdot 6$ & 4.7 & $22 \cdot 0$ & $43 \cdot 5$ & $2 \cdot 2$ & 1.7 & 1.7 & $3 \cdot 1$ & $2 \cdot 6$ & $1 \cdot 2$ & 0.9 & $1 \cdot 5$ & 6.7 & $100 \cdot 0$ & \\
\hline
\end{tabular}

for approximately $10 \%$ each with only one case each of internal and 'other trunk' injuries.

The most common cause of death was by drowning. The second most common site of injury causing death was the head, half of which were due to skiing/mountaineering accidents. The proportion due to each site is shown in Figure 7.

\section{Discussion}

The database used in the compilation of this paper restricted to information relating to admission to of medical establishment necessitating an overnight stay (if cluding people brought in dead). This necessarily excludes injuries referred to hospital which did not require admiso sion and includes admissions caused by factors other tha 


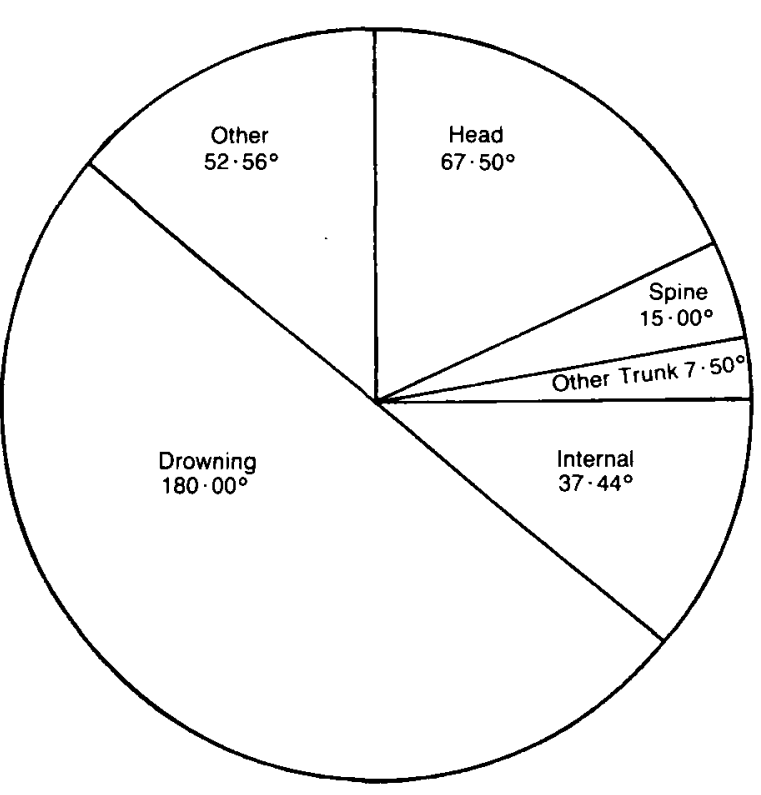

Fig. 7 Deaths by site.

the severity of the injuries. It also excludes the very large number of injuries treated by the GP and in outpatient departments which represent a very large loss of manpower.

Men only, officers and other ranks, were studied, as the women would exhibit entirely different trends and, therefore, need to be studied separately. The small number of women involved would also have inhibited a meaningful comparison.

Time Trends: The most interesting point to note is the falling trend in the number and rate of sports injuries until 1979 and then the rise in 1980 . The falling trend could be due to a number of factors, such as better standards of fitness, more training and supervision. However, the rise is more difficult to explain.

The rate of medical discharges changes from a falling trend to a rising one about 1974. This is particularly curious since the number of all medical discharges fell quite considerably during this time. Part of the change, apparently, could be caused by coding changes in respect of 'Late Effects'. The small number of deaths prevents detailed analysis of time trends.
Sport: Most inpatient admissions from sports injuries occur in soccer but this was also the most widely played $z$ sport in the Army (and one would presume the other Ser- $\stackrel{\mathbb{D}}{\square}$ vices) in 1962 according to Rosenbaum ${ }^{4}$, so soccer is not $\bigcirc$ necessarily the most dangerous. Using Rosenbaum as a guide of how much sport is played it was found that rugby is the most dangerous sport, producing one injury in alter- $\overrightarrow{\bar{B}}$ nate playing periods. However, Rosenbaum's data was collected in 1962 and playing trends may well have changed over the years, which would affect results.

It is worth noting at this point that half of the deaths were caused by drowning, either swimming/diving or boating, so perhaps this is indicative of a need for swim- $\tilde{\omega}$ ming instruction.

Age: It would appear that younger men are injured more of ten than older men although the numbers actually $\vec{\omega}$ playing sport probably affects the proportions. Older men tend not to get so involved in the more dangerous sports, and in sport in general, so they would be less at risk. Also older men tend to be more skilful and so less prone to accidents.

Site: A topical area of study is that of spinal injuries particularly those caused by playing rugby or doing gym nastics. J R Silver has already studied rugby injuries i the civilian population ${ }^{5}$ so the records of the 14 men whoo were medically discharged as a result of spinal injury caus, ed by PT were extracted (there were no deaths). Excep for one unknown case, all of the accidents occurred whis the man was on duty, and five of the men were involved in display teams which would imply a high level of com $\vec{\emptyset}$ petence. Of the 14,10 were at least partly paralysed of ? had limited movement, the others had recurrent back. ache. The presence of the five display team membef? shows that it is not only the inexperienced men who suffer these injuries.

A useful follow up to this study would be a survey, similar to Rosenbaum's, into how much sport is played in each Service. The Services could be studied separately to enable comparison and perhaps the Women's Services could be studied too.

\section{REFERENCES}

1. Oelman B J, Rose C M E and Arlow K J. Boxing Injuries in the Army. $J R$ Army Med Corps 1983; 129: 32-37.

2. NATO Forces supplement to the Manual of the ICD, STANAG 2050, 1962.

3. World Health Organisation Manual of the International Classification of Diseases, Injuries and Causes of Death, 8th and 9 th editions.

4. ROSEnBaum S. A survey of sport played in the Army. $J R A r$ my Med Corps 1967; 113: 65-74.

5 . SILVER J R. Injuries of the spine sustained in rugby. $\mathrm{Br}$ Med $J$ 1984; 288: 37-43. 